\title{
Effects of platelet rich plasma (PRP) on human gingival fibroblast, osteoblast and periodontal ligament cell behaviour
}

\author{
Eizaburo Kobayashi ${ }^{1,2}$, Masako Fujioka-Kobayashi ${ }^{1,3}$, Anton Sculean ${ }^{4}$, Vivianne Chappuis ${ }^{5}$, Daniel Buser ${ }^{5}$,
} Benoit Schaller ${ }^{1}$, Ferenc Döri ${ }^{6}$ and Richard J. Miron ${ }^{4,5,7,8^{*}}$

\begin{abstract}
Background: The use of platelet rich plasma (PRP, GLO) has been used as an adjunct to various regenerative dental procedures. The aim of the present study was to characterize the influence of PRP on human gingival fibroblasts, periodontal ligament (PDL) cells and osteoblast cell behavior in vitro.

Methods: Human gingival fibroblasts, PDL cells and osteoblasts were cultured with conditioned media from PRP and investigated for cell migration, proliferation and collagen1 (COL1) immunostaining. Furthermore, gingival fibroblasts were tested for genes encoding TGF- $\beta$, PDGF and COL1a whereas PDL cells and osteoblasts were additionally tested for alkaline phosphatase (ALP) activity, alizarin red staining and mRNA levels of osteoblast differentiation markers including Runx2, COL1a2, ALP and osteocalcin (OCN).

Results: It was first found that PRP significantly increased cell migration of all cells up to 4 fold. Furthermore, PRP increased cell proliferation at 3 and 5 days of gingival fibroblasts, and at 3 days for PDL cells, whereas no effect was observed on osteoblasts. Gingival fibroblasts cultured with PRP increased TGF- $\beta$, PDGF-B and COL1 mRNA levels at 7 days and further increased over 3-fold COL1 staining at 14 days. PDL cells cultured with PRP increased Runx2 mRNA levels but significantly down-regulated OCN mRNA levels at 3 days. No differences in COL1 staining or ALP staining were observed in PDL cells. Furthermore, PRP decreased mineralization of PDL cells at 14 days post seeding as assessed by alizarin red staining. In osteoblasts, PRP increased COL1 staining at 14 days, increased COL1 and ALP at 3 days, as well as increased ALP staining at 14 days. No significant differences were observed for alizarin red staining of osteoblasts following culture with PRP.

Conclusions: The results demonstrate that PRP promoted gingival fibroblast migration, proliferation and mRNA expression of pro-wound healing molecules. While PRP induced PDL cells and osteoblast migration and proliferation, it tended to have little to no effect on osteoblast differentiation. Therefore, while the effects seem to favor soft tissue regeneration, the additional effects of PRP on hard tissue formation of PDL cells and osteoblasts could not be fully confirmed in the present in vitro culture system.
\end{abstract}

Keywords: Platelet rich plasma, Platelet concentrates, Growth factor release, Periodontal regeneration

\footnotetext{
* Correspondence: rmiron@nova.edu

${ }^{4}$ Department of Periodontology, School of Dental Medicine, University of Bern, Bern, Switzerland

${ }^{5}$ Department of Oral Surgery and Stomatology, School of Dental Medicine,

University of Bern, Bern, Switzerland

Full list of author information is available at the end of the article
} 


\section{Background}

Various regenerative modalities in modern dental medicine have been investigated in recent years with the aim of either speeding hard or soft tissue regeneration or optimising the regenerative outcomes [1-4]. One of these modalities frequently promoted has been the utilization of growth factors including platelet derived growth factor (PDGF) and bone morphogenetic proteins (BMPs) $[4,5]$. While the use of such growth factors has been shown to speed the quality of either hard or soft tissue formation specifically when combined with various biomaterials including barrier membranes and bone grafting materials, some disadvantages such as high costs, high supra-physiological doses of growth factors, as well as unwanted side effects associated with recombinant therapies have also been reported [6-8].

Interestingly, the use of platelet rich plasma (PRP) contains plasma with up to a 5 -fold increase in platelet concentrations [9], has been shown to improve growth factor concentrations from whole blood by centrifugation to reach supra-physiological doses [10, 11]. Reported advantages include having higher biocompatibility as well as relatively low costs associated with their treatment [12-17]. Initial experiments revealed that PRP contained high levels of PDGF compared to whole blood capable of modulating tissue wound healing [9, 17-21]. Other investigators have hypothesized that bone healing could be improved due to the angiogenetic, proliferative and/or differentiating effects of PRP on various cell types [19, 22-24]. While initial experiments hypothesized over such advantages, data from the literature have shown mixed results following the use of PRP as a regenerative material for bone and periodontal regeneration [17, 25-39].

Since PRP has now been utilized in the field of periodontology for over a decade with various results, the aim of the present study was to perform one of the largest known in vitro studies on the topic by utilizing 3 different cell-types involved with periodontal regeneration including human gingival fibroblasts, osteoblasts and periodontal ligament (PDL) cells. Currently, there remains controversial results for studies that have attempted to determine the bone-healing and soft tissue-healing potential of PRP. Therefore, this in vitro study was utilized to better characterize the regenerative potential of conditioned media from a new formulation of PRP (GLO PRP) on each cell type with direct comparison over their regenerative potential being possible within the same study.

\section{Methods}

\section{Platelet concentrates}

Blood samples were harvested with the informed consent of 6 volunteer donors (from Bern Switzerland) and further processed into PRP. No IRB was required for the present study as blood was used in a non-identifiable manner and the IRB waived its requirement (Bern, Switzerland). The PRP was prepared utilizing the GLO PRP kit. Briefly, $1 \mathrm{ml}$ of sodium citrate anticoagulant was added into the GLO PRP tube and $9 \mathrm{ml}$ of blood was then taken from the donor. Thereafter the red blood cell collector was attached firmly on the tip of the GLO PRP tube and the plunger removed by turning it counter clockwise and the blood + anticoagulant was shaken gently. The first centrifuge was then performed at $1200 \mathrm{~g}$ for $5 \mathrm{~min}$ and thereafter the remaining red blood cells were flushed out from the tube to separate them. The remaining tube was re-centrifuged for a second time at $1200 \mathrm{~g}$ for $10 \mathrm{~min}$. Thereafter, platelet poor plasma (PPP) and PRP were separated using a $5 \mathrm{ml}$ syringe with needle to collect the PPP. The remaining PRP was further utilized for experimental seeding as later indicated. Blood was collected from members of our laboratory (30 to 60 years of age).

Thereafter PRP was transferred to 6 well culture dishes with $5 \mathrm{~mL}$ of cell culture media and processed for further investigation as previously described [40-42]. PRP was incubated for 3 days in a spinning chamber at $37^{\circ} \mathrm{C}$ and conditioned media (CM) was collected and utilized for future experiments as a $20 \%$ total volume dose.

\section{Protein quantification with ELISA}

ELISA was utilized to quantify the total amount of growth factors released from PRP at $15 \mathrm{~min}, 60 \mathrm{~min}$, 8 h, 1 day, 3 days and 10 days. All PRP samples were harvested and placed in a shaking incubator at $37{ }^{\circ} \mathrm{C}$ where growth factors were gradually released over time and collected from standard tissue culture media. At each time point, media was collected and replaced with a fresh $5 \mathrm{~mL}$ of media and frozen for later processing. Standing ELISA was utilized to quantify proteins according to the manufacturer's protocols as previously described [43]. Absorbance was measured at 450 and $570 \mathrm{~nm}$ on an ELx808 Absorbance Reader (BIO-TEK, Winooski, VT) and samples were quantified in triplicate with 3 independent experiments performed.

\section{Cell isolation and culture}

Primary human gingival tissues were obtained from three healthy donors under-going third molar extraction as previous described [44]. Similarly, primary osteoblasts were also cultured from bone tissue during removal of impacted $3^{\text {rd }}$ molars as previously described $[45,46]$. Primary human PDL cells were harvested from the middle third portion of healthy extracted teeth (for normal standard care) with no signs of periodontal disease extracted for orthodontic reasons as previously described [45, 46]. Cells from each tissue type (1. gingival fibroblasts, 2. osteoblasts and 3. PDL cells) were collected from 3 separate donors and pooled with similar cell-types. No 
IRB was required for the present study as cells were collected in a non-identifiable manner and the IRB waived its requirement (Bern, Switzerland). An ethical approval with informed written consent was obtained from all patients. All cells were detached from tissue culture plastic using 0.25\% EDTA-Trypsin (Gibco, Life technologies, Carlsbad, CA) prior to reaching confluency. Cells were cultured in a standard humidified atmosphere at $37{ }^{\circ} \mathrm{C}$ in of DMEM (Gibco), 10\% fetal bovine serum (FBS; Gibco) with $1 \%$ antibiotics (Gibco). Cells (passage 4-6) were seeded with $20 \%$ conditioned media from PRP for experimental purposes as previously described [47]. 10,000 cells were utilized for cell proliferation experiments and 50,000 cells were utilized for real-time PCR, immunofluorescent staining, ALP assay and alizarin red experiments in 24 well culture dishes.

\section{Cell viability}

Primary human gingival fibroblasts, PDL cells and osteoblasts were seeded at a density of 10 '000 cells per 24-well plate on control tissue culture plastic, with $20 \%$ conditioned media from PRP and 10\% FBS. At $24 \mathrm{~h}$ post cell seeding, a live-dead staining assay was used to assess cell viability (Enzo Life Sciences AG; Lausen, Switzerland) as previously described [48]. Thereafter, the percentage of live versus dead cells was utilized to quantify cell viability.

\section{Cell migration assay}

A Boyden chamber was utilized to investigate migration of cells using 24-well plates and polyethylene terephthalate filters with a pore size of $8 \mu \mathrm{m}$ (ThinCertTM, Greiner Bio-One GmhH, Frickenhausen, Germany). PRP conditioned media (20\%) in DMEM containing 10\% FBS was placed into the lower wells as previously described [40, 49]. After starving the cells in DMEM containing 0.5\% FBS for $12 \mathrm{~h}, 10,000$ cells were seeded in the upper compartment and after $24 \mathrm{~h}$, the number of migrated cells on the lower side of the filter were counted under a microscope as previously described [40, 49].

\section{Proliferation assay}

Ten thousand primary human gingival fibroblasts, PDL cells and osteoblasts were seeded in 24-well culture plates with $20 \%$ conditioned media from PRP. An MTS assay was utilized to quantify cells (Promega, Madison, WI) at 1,3 and 5 days as previously described $[46,50]$. At desired time points, cells were washed with phosphate buffered solution (PBS) and quantified using a ELx808 Absorbance Reader.

\section{Real-time PCR analysis}

Total RNA was harvested at 3 and 7 days post stimulating for gingival fibroblasts to investigate mRNA levels of
TGF- $\beta$, PDGF-A, PDGF-B and collagen1a2 (COL1a2). For PDL cells and osteoblasts, osteoblast differentiation markers including Runx2, COL1a2, alkaline phosphatase (ALP) and osteocalcin (OCN) mRNA levels were investigated at 3 and 14 days post-seeding. Table 1 reports the primer and probe sequences for genes. RNA isolation (High Pure RNA Isolation Kit, Roche, Switzerland) and real-time RT-PCR (Roche Master mix on an Applied Biosystems 7500 Real-Time PCR machine) was then performed. A Nanodrop 2000c (Thermo, Wilmington, DE) was utilized to calculate total RNA levels. The $\Delta \Delta \mathrm{Ct}$ method was utilized to calculate gene expression levels normalized to the expression of GAPDH.

\section{ALP activity assay}

PDL cells and osteoblasts were stimulated with 20\% conditioned media from PRP with and without osteogenic differentiation medium (ODM), which consisted of DMEM supplemented with $10 \%$ FBS, $1 \%$ antibiotics, $50 \mu \mathrm{g} / \mathrm{ml}$ ascorbic acid (Sigma, St. Louis, MO) and $10 \mathrm{mM} \beta$-glycerophosphate (Sigma) to induce osteoblast differentiation as previously described [51]. The ALP assay was performed using the Leukocyte alkaline phosphatase kit (procedure No. 86, Sigma) as previously described [45, 52-55].

\section{Mineralization assay}

Alizarin red staining was used to determine osteoblast mineralization. After 14 days, cells were stained followed by $0.2 \%$ alizarin red solution staining $(\mathrm{pH} 6.4)$ as previously described $[45,50,51,56,57]$.

Table 1 List of primer sequences for real-time PCR

\begin{tabular}{ll}
\hline Gene & Primer Sequence \\
\hline hTGF- $\beta$ F & actactacgccaaggaggtcac \\
hTGF- $\beta$ R & tgcttgaacttgtcatagatttcg \\
hPDGF-A F & cacacctcctcgctgtagtattta \\
hPDGF-A R & gttatcggtgtaaatgtcatccaa \\
hPDGF-B F & tcccgaggagcttatgaga \\
hPDGF-B R & actgcacgttgcggttgt \\
hCOL1a2 F & cccagccaagaactggtatagg \\
hCOL1a2 R & ggctgccagcattgatagtttc \\
hRunx2 F & tcttagaacaaattctgcccttt \\
hRunx2 R & tgctttggtcttgaaatcaca \\
hALP F & gacctcctcggaagacactc \\
hALP R & tgaagggcttcttgtctgtg \\
hOCN F & agcaaaggtgcagcctttgt \\
hOCN R & gcgcctgggtctcttcact \\
hGAPDH F & agccacatcgctcagacac \\
hGAPDH R & gcccaatacgaccaaatcc \\
\hline
\end{tabular}




\section{Collagen immunofluorescent staining}

Human gingival fibroblasts, PDL cell and osteoblasts were plated at a density of 50,000 cells per structure in a 24-well plate containing $20 \%$ conditioned media from PRP. At 14 days post seeding, cells were fixed and stained with collagen type I antibodies (sc-28657, Santa Cruz, California, USA) diluted 1:100 in PBS containing $1 \%$ BSA as previously described.

\section{Statistical analysis}

Three independent experiments performed in triplicate were utilized for all conditions. Means and standard errors (SE) were calculated and data were analyzed for statistical significance using standard t-test (2 groups), one way analysis of variance (ANOVA) with Tukey test by GraphPad Prism 6.0 software.

\section{Results}

Release of growth factors from PRP

In a first series of experiments, the total amount of growth factors released from PRP including PDGF-AA, PDGF-AB, PDGF-BB, TGF- $\beta 1$, VEGF, IGF and EGF was investigated at various time points including $15 \mathrm{~min}$, $60 \mathrm{~min}, 8 \mathrm{~h}, 1$ day, 3 days, and 10 days. It was found that of all the growth factors, PDGF-AA released the highest total amount of growth factor followed by TGF- $\beta 1$ (Fig. 1). Interestingly, most of the growth factor release occurred at early time points (15 and $60 \mathrm{~min}$ ), whereas little release of growth factor was seen at later time points up to a 10 day period. Figure $1 \mathrm{~b}$ demonstrates the total growth factor release accumulated in the culture media over a 10 day period. The release of VEGF, IGF and EGF followed similar trends whereby growth factor release occurred at early time points (15 and $60 \mathrm{~min})$ and was maintained up to a 10 day period (data not shown). The total growth factor release from each donor is summarized in Table 2 along with the minimum, maximum and average values.

Cell viability of gingival fibroblasts, PDL cells and osteoblasts in response to PRP

In a first set of experiments, we sought to characterize the influence of conditioned media from PRP on cell viability of 3 cell types including gingival fibroblasts, PDL cells and osteoblasts (Fig. 2). It was found that all cells displayed no significant changes in cell viability following $24 \mathrm{~h}$ cell culture with and without PRP. Therefore, it was initially confirmed that PRP is fully biocompatible under the present in vitro cell culture model and future experiments were designed thereafter to investigate its effect on cell behaviour (Figs. 3, 4 and 5).

\section{Influence of PRP on human gingival fibroblasts}

Following cell survival investigation, conditioned media from PRP was then investigated on gingival fibroblast cell behaviour (Fig. 3). It was first observed that PRP induced a 4-fold significant increase in cell migration of gingival fibroblasts at $24 \mathrm{~h}$ (Fig. 3a). Furthermore, PRP

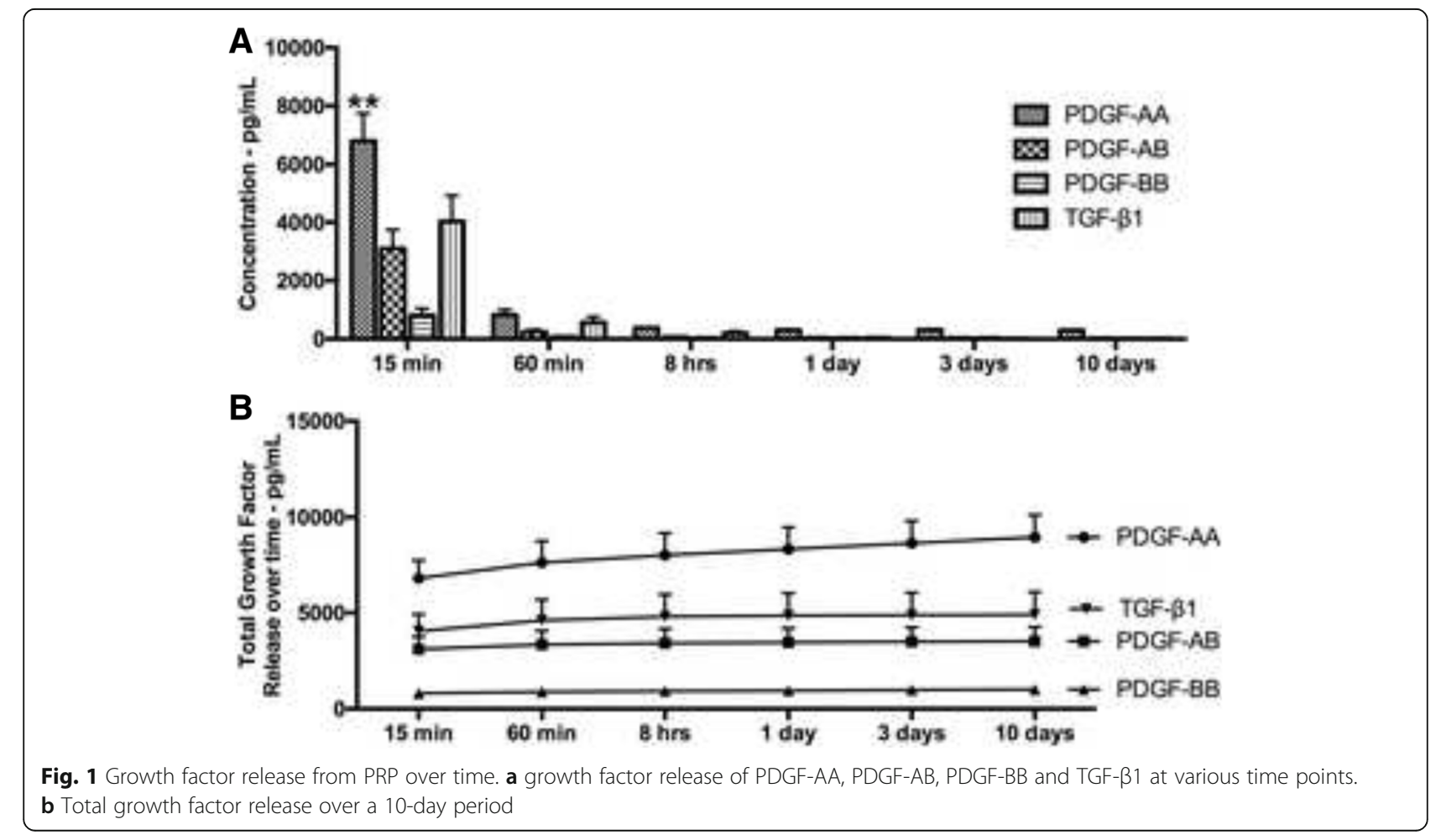


Table 2 Total growth factors released over 10 days from PRP. Data represents averages $(\mathrm{pg} / \mathrm{ml})$ with ranges (minimum to maximum values)

\begin{tabular}{llll}
\hline & PRP - minimum & PRP - average & PRP - maximum \\
\hline PDGF-AA & 5968 & 8954 & 15787 \\
PDGF-AB & 1644 & 3522 & 8179 \\
PDGF-BB & 415 & 1020 & 2761 \\
TGF- $\beta 1$ & 366 & 4909 & 12414 \\
VEGF & 187 & 331 & 486 \\
EGF & 77 & 182 & 344 \\
IGF & 511 & 987 & 1728 \\
\hline
\end{tabular}

also significantly increased cell proliferation of gingival fibroblasts at 3 and 5 days post seeding (Fig. 3b). Real time PCR demonstrated that PRP significantly increased regenerative mRNA levels of growth factors including TGF- $\beta$, PDGF-B and COL1a2 at 7 days post seeding (Fig. 3c). Immunofluorescent staining of COL1 at 14 days further demonstrated a $300 \%$ increase in COL1 staining when compared to gingival fibroblasts cultured on control tissue culture plastic without PRP (Fig. 3d, e).

\section{Influence of PRP on human PDL cells}

Thereafter, conditioned media from PRP was investigated on PDL cell behaviour (Fig. 4). It was found that PRP significantly increased cell migration at $24 \mathrm{~h}$ (Fig. 4a) and cell proliferation at 3 days (Fig. 4b) however the effects were much less pronounced when compared to gingival fibroblasts. Real time PCR for osteoblast differentiation markers including genes encoding Runx2, COL1a2, ALP and OCN did not seem to show any trend towards improving their differentiation towards osteoblasts/cementoblasts by demonstrating no changes in COL1a2 and ALP mRNA levels at both 3 and 14 days post seeding (Fig. 4c). Interestingly, PRP significantly increased mRNA levels of Runx2 at 3 days, however not at 14 days, whereas mRNA levels of OCN were significantly down-regulated at 3 days with no differences found at 14 days (Fig. 4c).

Thereafter, COL1 immunofluorescent staining as well as ALP staining showed no preference for PRP when compared to control tissue culture plastic (Fig. 4d, e). PRP also failed to promote the mineralization potential of PDL cells at 14 days by demonstrating significantly lower levels of alizarin red staining at 14 days post seeding (Fig. 4f).

\section{Influence of PRP on human osteoblasts}

Lastly, the effect of conditioned media from PRP was investigated on human osteoblasts (Fig. 5). It was first observed that PRP significantly increased osteoblast migration at $24 \mathrm{~h}$ (Fig. 5a). No effect on osteoblast proliferation was seen at either 1,3 or 5 days post seeding (Fig. 5b). Real-time PCR demonstrated that PRP significantly increased COL1a2 and ALP mRNA levels at 3 days, as well as Runx2 mRNA levels at 14 days post seeding (Fig. 5c). No significant difference in OCN mRNA levels was observed at either 3 or 14 days post-seeding following osteoblast culture with PRP (Fig. 5c).
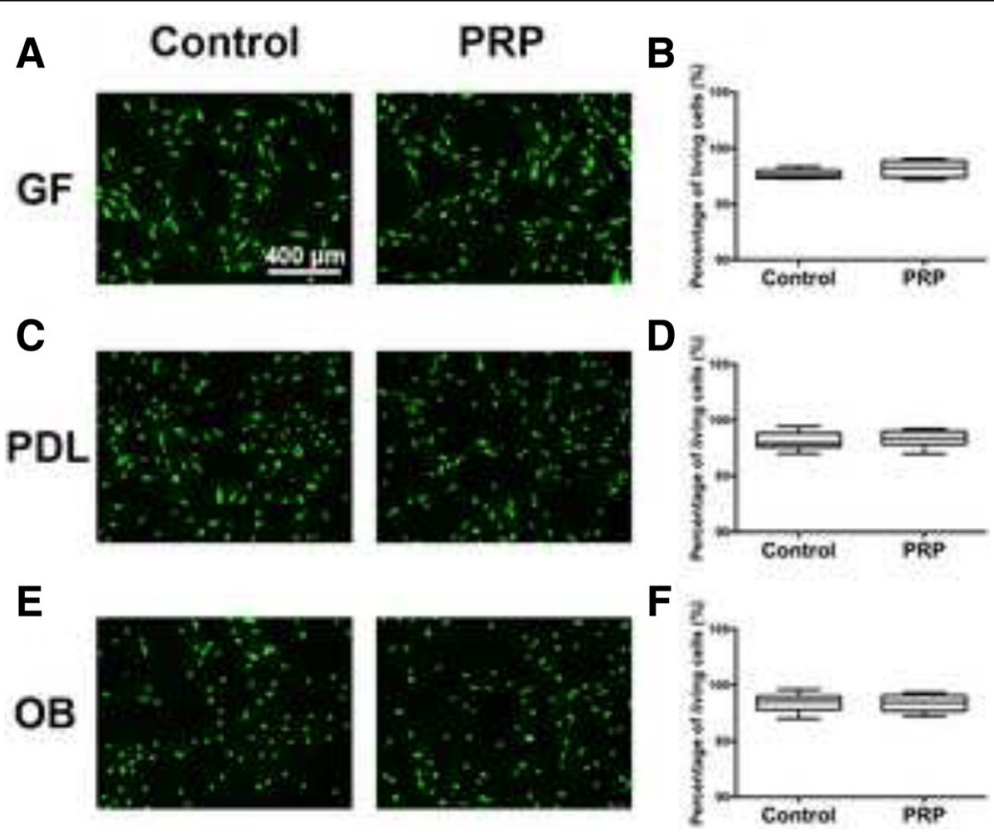

Fig. 2 Live/Dead assay of PRP. Live/Dead assay at 24 h of primary human gingival fibroblasts (GF) (a, b), PDL cells (PDL) (c, d) and osteoblasts $(\mathrm{OB})(\mathbf{e}, \mathbf{f})$ in response to cell culture with PRP. No significant changes in cell viability were observed for all platelet concentrates 

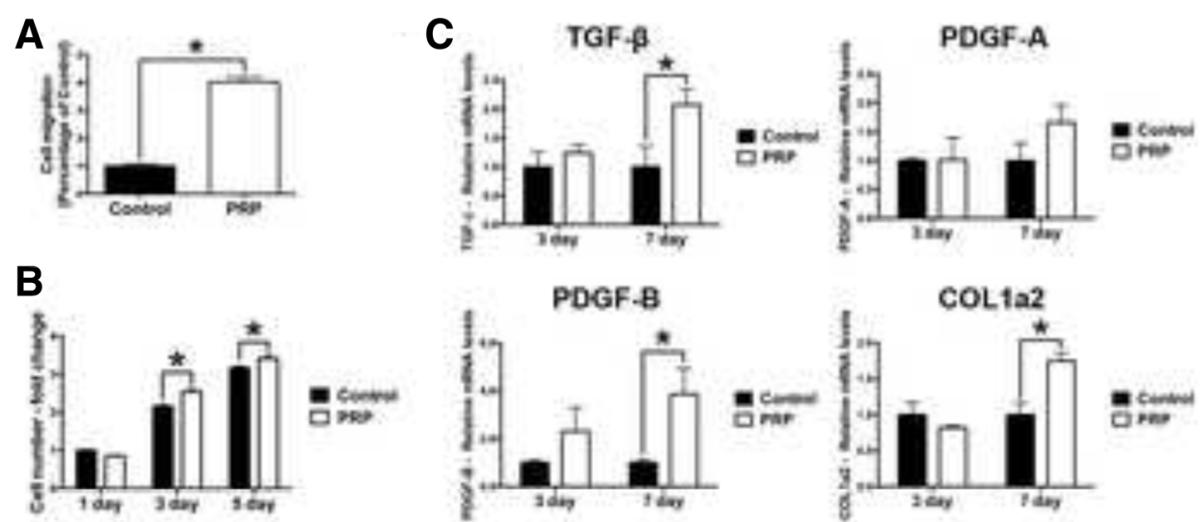

D

Control

PRP

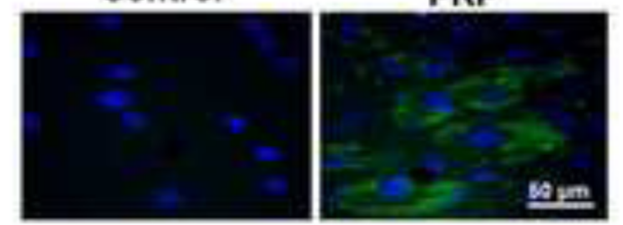

$\mathbf{E}$

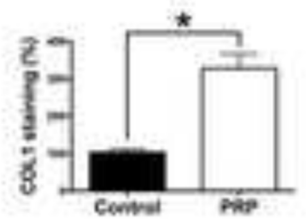

Fig. 3 Effect of PRP on human gingival fibroblasts. Human primary gingival fibroblast cultured with PRP on (a) cell migration at $24 \mathrm{~h}$, (b) proliferation at 1, 3 and 5 days, (c) real-time PCR at 3 and 7 days for mRNA levels of TGF- $\beta$, PDGF-A, PDGF-B and COL1a2, as well as (d, e) immunofluorescent collagen 1 (COL1) staining at 14 days. (Data presents means and standard error bars; ${ }^{*}$ denotes significant difference between groups, $p<0.05)$

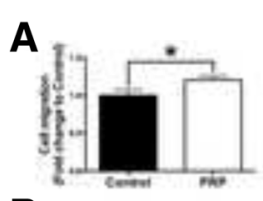

B

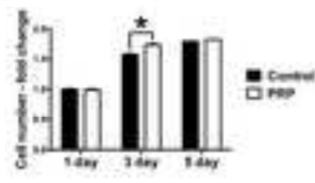

D

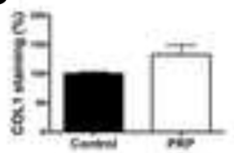

E

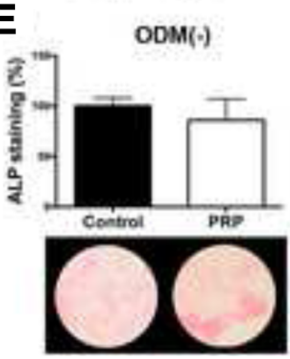

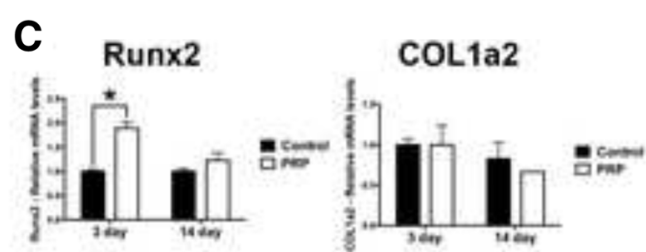

ALP
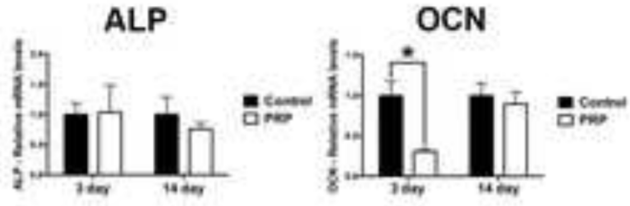

$\mathbf{F}$
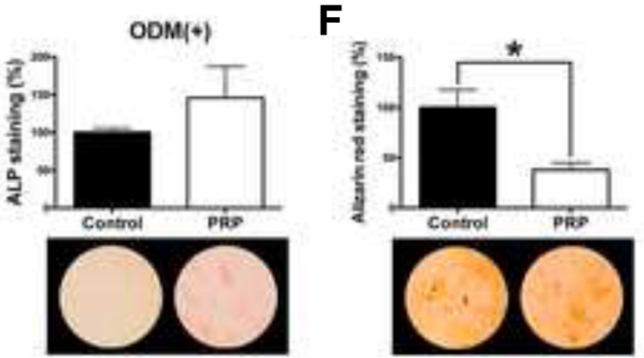

Fig. 4 Effect of PRP on human periodontal ligament cells. Human PDL cells cultured with PRP on (a) cell migration at $24 \mathrm{~h}$, (b) cell proliferation at 1, 3 and 5 days, (c) real-time PCR at 3 and 14 days for mRNA levels of osteoblast differentiation markers including Runx2, COL1a2, ALP and OCN, (d) immunofluorescent COL1 staining at 14 days, (e, f) ALP staining both with and without osteoblast differentiation media (ODM) at 14 days, as well as (f) alizarin red staining denoting mineralization at 14 days post seeding. (Data presents means and standard error bars; ${ }^{*}$ denotes significant difference between groups, $p<0.05)$ 

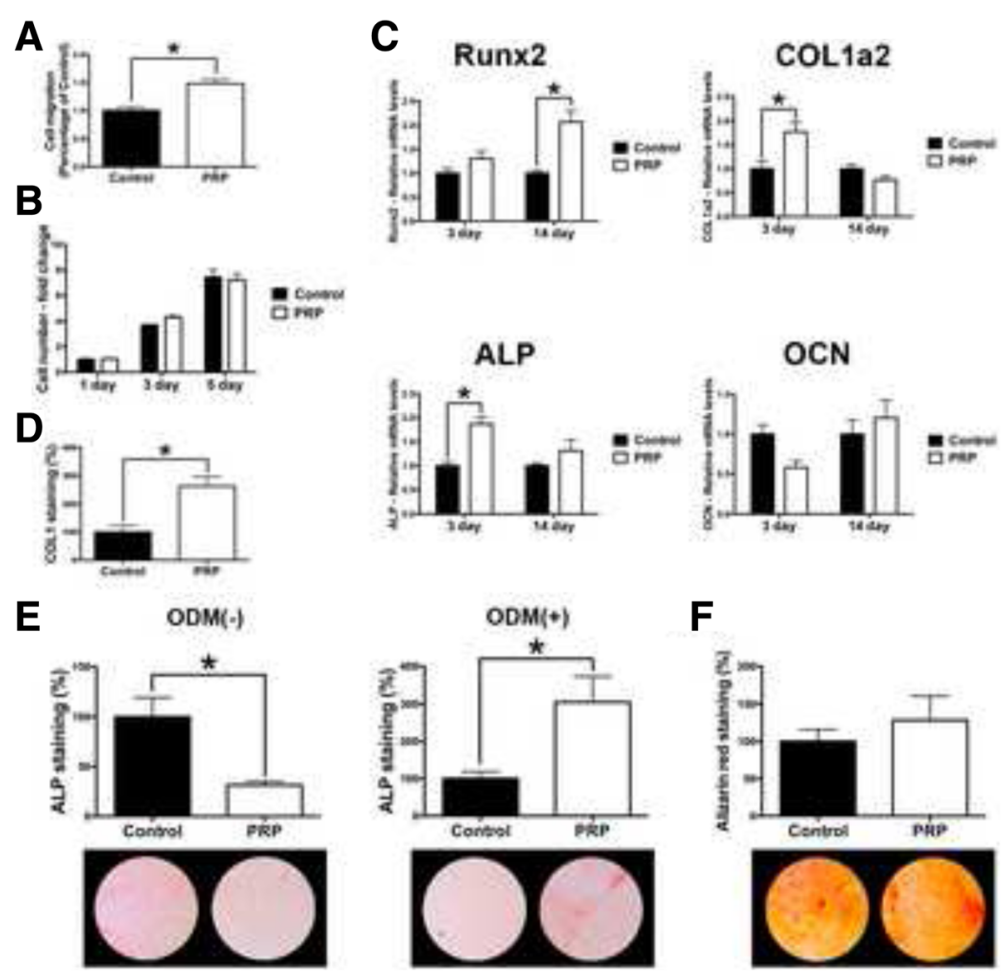

Fig. 5 Effect of PRP on human osteoblasts. Human osteoblasts cultured with PRP on (a) cell migration at 24 h, (b) cell proliferation at 1, 3 and 5 days, (c) real-time PCR at 3 and 14 days for mRNA levels of osteoblast differentiation markers including Runx2, COL1a2, ALP and OCN, (d) immunofluorescent COL1 staining at 14 days, (e, f) ALP staining both with and without osteoblast differentiation media (ODM) at 14 days, as well as (f) alizarin red staining denoting mineralization at 14 days post seeding. (Data presents means and standard error bars; * denotes significant difference between groups, $p<0.05)$

Thereafter, it was found that PRP significantly promoted a 2.5 fold increase in COL1 immunofluorescent staining at 14 days post seeding (Fig. 5d). Interestingly, ALP staining without ODM found that PRP significantly decreased ALP staining whereas with ODM significantly promoted ALP staining at 14 days (Fig. 5e). No change in alizarin red staining was observed following osteoblast culture with PRP (Fig. 5f).

\section{Discussion}

The aim of the present study was to investigate the in vitro regenerative potential of conditioned media from PRP on 3 different cell-types involved in periodontal regeneration including gingival fibroblasts, PDL cells and osteoblasts. To date, no study has performed such a widespread in vitro analysis on the performance of PRP (from GLO systems) on these cell-types. Furthermore, new spin cycle protocols and various formulation of platelet concentrates are routinely brought to market and it is therefore of clinical interest and significance to investigate their individual performances [15, 47, 58, 59].

Recently, we investigated the release of various growth factors from 3 different platelet concentrates [58]. It was first found that PRP, in comparison to PRF, released higher amounts of growth factors including PDGF, TGF- $\beta$ and VEGF at early time points (15 and $60 \mathrm{~min}$ ) and therefore favoured the early release of growth factors for regenerative procedures [58]. In the present study, we also found that this different formulation of PRP, spun with pre-existing columns to separate platelet concentrates, also formulated a PRP with a release profile of growth factors similar to previous formulations of PRP. Interestingly however, a slight increase in total growth factor, most likely resulting from the present system utilized was noticed.

The concentrated growth factors released from PRP was then investigated on the migration and proliferation of various cell-types from the oral cavity (Figs. 2, 3 and 4). Interestingly, it was found that gingival fibroblasts demonstrated the ability to further promote cell migration and proliferation in response to PRP when compared to PDL cells and osteoblasts. Furthermore, COL1 staining was also more significantly upregulated in gingival fibroblasts when compared to PDL cells and osteoblasts. Interestingly, it was observed that PRP had no effect on the ALP activity of PDL cells and actually significantly down-regulated in vitro mineralization potential of PDL cells by demonstrating lower levels of alizarin red staining (Fig. 4) whereas its effect on osteoblasts demonstrated 
little to no changes in mineralization potential (Fig. 5). It may therefore be concluded that while PRP showed little to no potential to induce osteoblast differentiation (new bone formation), its effects seemed to favour gingival fibroblast regeneration (soft tissue wound healing). Future animal models are however necessary to further confirm these in vitro findings.

Over the years, numerous investigations have been performed to determine the regenerative potential of PRP for both soft and hard tissue regeneration [60-62]. For instance, Graziani et al. previously investigated the biological rationale of PRP by evaluating its effect at different concentrations on fibroblasts and osteoblasts activity in vitro [62]. It was found that PRP preparations exerted a dose-specific effect on oral fibroblasts and osteoblasts. Interestingly, increased concentrations resulted in a reduction in proliferation and a suboptimal effect on osteoblast function primarily [62]. Griffin et al. showed in a systematic review that although early clinical results suggest that the use of PRP is safe and feasible, however presents with no clinical benefit in either acute or delayed fracture healing was observed and therefore its use in bone regeneration was not undetermined [61]. While other models have also shown favorable results on new bone formation with platelet concentrates [63-65], the results from our study showed that PRP had little influence on osteoblast differentiation (Fig. 5). Therefore and in combination with some of the previous published studies, it may be suggested that PRP induced a strong potential for soft-tissue regeneration by demonstrating marked increases in gingival fibroblast cell migration, proliferation, release of growth factor and collagen synthesis (Fig. 3) yet has no obvious potential to induce or enhance new bone formation. Although several advantages existed when PRP was combined with PDL cells and osteoblasts including increased cell migration, proliferation or collagen synthesis, these marked increases were less pronounced and did not seem to contribute to their differentiation or mineralization potential at least in vitro.

\section{Conclusions}

The results from the present study demonstrated that PRP is able to release supra-physiological doses of plateletderived growth factors including PDGF-AA, PDGF-AB, PDGF-BB, TGF- $\beta 1$, VEGF, EGF and IGF at varying concentrations for up to 10 days. While PRP was extremely biocompatible with all cell-types, it can be hypothesized that PRP is able to induce greater soft tissue regeneration by significantly increasing the stimulation of gingival fibroblast behaviour when compared to PDL cells or osteoblasts. Little effects, however, were observed for PRP on osteoblasts differentiation or mineralization potential of PDL cells and osteoblasts in vitro. Future animal testing is thus required to further evaluate the regenerative potential of PRP in both soft and hard tissue formation.

\begin{abstract}
Abbreviations
ALP: Alkaline phosphatase; BMP2: Bone morphogenetic protein 2;

COL1: Collagen1; EGF: Epidermal growth factor; ELISA: Enzyme-Linked Immunosorbent Assay; IGF: Insulin growth factor; IRB: Internal Review Board; OCN: Osteocalcin; ODM: Osteogenic differentiation medium; PBS: Phosphate buffered solution; PDGF: Platelet-derived growth factor; PDL: Periodontal Ligament; PPP: Platelet poor plasma; PRP: Platelet rich Plasma; SE: Standard error; TGF $\beta 1$ : Transforming growth factor Beta 1; TGF $\beta 1$ : Transforming growth factor beta-1; VEGF: Vascular endothelial growth factor
\end{abstract}

\section{Acknowledgements}

Not applicable.

\section{Funding}

This study was funded by the Department of Cranio Maxillofacial Surgery, Inselspital, University of Bern, Switzerland.

\section{Availability of data and materials}

The datasets used and/or analyzed during the current study available from the corresponding author on reasonable request.

\section{Authors' contributions}

EK and MFK carried out the molecular analysis, and ELISAs. BS, VC, DB, AS, FD and RJM drafted the manuscript. All authors participated in the design of the study. MFK and EK performed the statistical analysis. All authors read, corrected and approved the final manuscript.

\section{Competing interest}

Anton Sculean is an editorial board member for BMC Oral Health. The other authors all declare that they have no competing interests.

\section{Consent for publication}

Not applicable.

\section{Ethics approval and consent to participate}

All blood samples were collected in Bern, Switzerland and utilized in accordance to the guidelines by the University of Bern ethical standards and guidelines via an IRB process (Internal Review Board). An ethical request from the local Canton of Bern (Switzerland) was waived by the IRB (Canton of Bern) for this study since blood was not used as identifiable sources. Blood samples were collected with the informed consent of 6 volunteer donors from Bern, Switzerland. Human cells were used from previous studies that were frozen in a tissue bank with non-identifiable sources approved by our Ethics department at the Canton of Bern (Switzerland).

\section{Publisher's Note}

Springer Nature remains neutral with regard to jurisdictional claims in published maps and institutional affiliations.

\section{Author details \\ ${ }^{1}$ Department of Cranio-Maxillofacial Surgery, University Hospital, University of Bern, Bern, Switzerland. '2Department of Oral and Maxillofacial Surgery, School of Life Dentistry at Niigata, The Nippon Dental University, Niigata, Japan. ${ }^{3}$ Department of Oral Surgery, Clinical Dentistry, Institute of Biomedical Sciences, Tokushima University Graduate School, Tokushima, Japan. \\ ${ }^{4}$ Department of Periodontology, School of Dental Medicine, University of Bern, Bern, Switzerland. ${ }^{5}$ Department of Oral Surgery and Stomatology, School of Dental Medicine, University of Bern, Bern, Switzerland. \\ ${ }^{6}$ Department of Periodontology, Semmelweis University, Budapest, Hungary. ${ }^{7}$ Department of Periodontology, College of Dental Medicine, Nova Southeastern University, Fort Lauderdale, FL, USA. ${ }^{8}$ Cell Therapy Institute, Center for Collaborative Research, Nova Southeastern University, Fort Lauderdale, FL, USA.}

Received: 8 June 2016 Accepted: 22 May 2017

Published online: 02 June 2017

References

1. Dohan Ehrenfest DM, Wang HL, Galindo-Moreno P, Bowler D, Dym H. Bone morphogenic protein: application in implant dentistry. Biomed Res Int. 2015; 59(2):493-503. 
2. Padial-Molina M, O'Valle F, Lanis A, Mesa F. Clinical application of mesenchymal stem cells and novel supportive therapies for oral bone regeneration. Biomed Res Int. 2015;2015:341327.

3. Sanz-Sanchez I, Ortiz-Vigon A, Sanz-Martin I, Figuero E, Sanz M. Effectiveness of lateral bone augmentation on the alveolar crest dimension: a systematic review and meta-analysis. J Dent Res. 2015;94(9 Suppl):128s-42s.

4. Miron RJ, Zhang YF. Osteoinduction: a review of old concepts with new standards. J Dent Res. 2012;91 (8):736-44.

5. Kaigler D, Avila G, Wisner-Lynch L, Nevins ML, Nevins M, Rasperini G, Lynch SE, Giannobile W. Platelet-derived growth factor applications in periodontal and peri-implant bone regeneration. Expert Opin Biol Ther. 2011;11(3):375-85.

6. Anusaksathien O, Giannobile W. Growth factor delivery to re-engineer periodontal tissues. Curr Pharm Biotechnol. 2002;3(2):129-39.

7. Carreira AC, Lojudice FH, Halcsik E, Navarro RD, Sogayar MC, Granjeiro JM. Bone morphogenetic proteins: facts, challenges, and future perspectives. J Dent Res. 2014;93(4):335-45.

8. Rocque BG, Kelly MP, Miller JH, Li Y, Anderson PA. Bone morphogenetic protein-associated complications in pediatric spinal fusion in the early postoperative period: an analysis of 4658 patients and review of the literature. J Neurosurg Pediatr. 2014;14(6):635-43.

9. Marx RE, Carlson ER, Eichstaedt RM, Schimmele SR, Strauss JE, Georgeff KR. Platelet-rich plasma: growth factor enhancement for bone grafts. Oral Surg Oral Med Oral Pathol Oral Radiol Endod. 1998;85(6):638-46.

10. Del Corso M, Vervelle A, Simonpieri A, Jimbo R, Inchingolo F, Sammartino G, Dohan Ehrenfest DM. Current knowledge and perspectives for the use of platelet-rich plasma (PRP) and platelet-rich fibrin (PRF) in oral and maxillofacial surgery part 1: periodontal and dentoalveolar surgery. Curr Pharm Biotechnol. 2012;13(7):1207-30

11. Simonpieri A, Del Corso M, Vervelle A, Jimbo R, Inchingolo F, Sammartino G, Dohan Ehrenfest DM. Current knowledge and perspectives for the use of platelet-rich plasma (PRP) and platelet-rich fibrin (PRF) in oral and maxillofacial surgery part 2: bone graft, implant and reconstructive surgery. Curr Pharm Biotechnol. 2012;13(7):1231-56.

12. Medina-Porqueres I, Alvarez-Juarez P. The efficacy of platelet-rich plasma injection in the management of hip osteoarthritis: a systematic review protocol. Musculoskeletal Care. 2016;14(2):121-5.

13. Salamanna F, Veronesi F, Maglio M, Della Bella E. New and emerging strategies in platelet-rich plasma application in musculoskeletal regenerative procedures: general overview on still open questions and outlook. Biomed Res Int. 2015;2015:846045.

14. Albanese A, Licata ME, Polizzi B, Campisi G. Platelet-rich plasma (PRP) in dental and oral surgery: from the wound healing to bone regeneration. Immun Ageing. 2013;10(1):23.

15. Dohan Ehrenfest DM, Andia I, Zumstein MA, Zhang CQ, Pinto NR, Bielecki T. Classification of platelet concentrates (Platelet-Rich Plasma-PRP, Platelet-Rich Fibrin-PRF) for topical and infiltrative use in orthopedic and sports medicine: current consensus, clinical implications and perspectives. Muscles Ligaments Tendons J. 2014:4(1):3-9.

16. Maney P, Amornporncharoen M, Palaiologou A. Applications of plasma rich in growth factors (PRGF) in dental surgery: a review. J West Soc Periodontol Periodontal Abstr. 2013;61(4):99-104.

17. Panda S, Doraiswamy J, Malaiappan S, Varghese SS, Del Fabbro M. Additive effect of autologous platelet concentrates in treatment of intrabony defects: a systematic review and meta-analysis. J Investig Clin Dent. 2016:7(1):13-26.

18. Marx RE. Platelet-rich plasma (PRP): what is PRP and what is not PRP? Implant Dent. 2001;10(4):225-8.

19. Marx RE. Platelet-rich plasma: evidence to support its use. J Oral Maxillofac Surg. 2004;62(4):489-96.

20. Kukreja BJ, Dodwad V, Kukreja P, Ahuja S, Mehra P. A comparative evaluation of platelet-rich plasma in combination with demineralized freeze-dried bone allograft and DFDBA alone in the treatment of periodontal intrabony defects: a clinicoradiographic study. J Indian Soc Periodontol. 2014;18(5):618-23.

21. Pradeep AR, Rao NS, Agarwal E, Bajaj P, Kumari M, Naik SB. Comparative evaluation of autologous platelet-rich fibrin and platelet-rich plasma in the treatment of 3-wall intrabony defects in chronic periodontitis: a randomized controlled clinical trial. J Periodontol. 2012;83(12):1499-507.

22. Kawase T, Okuda K, Wolff LF, Yoshie H. Platelet-rich plasma-derived fibrin clot formation stimulates collagen synthesis in periodontal ligament and osteoblastic cells in vitro. J Periodontol. 2003;74(6):858-64.
23. Kanno T, Takahashi T, Tsujisawa T, Ariyoshi W, Nishihara T. Platelet-rich plasma enhances human osteoblast-like cell proliferation and differentiation. J Oral Maxillofac Surg. 2005;63(3):362-9.

24. He L, Lin $Y$, Hu X, Zhang $Y$, Wu H. A comparative study of platelet-rich fibrin (PRF) and platelet-rich plasma (PRP) on the effect of proliferation and differentiation of rat osteoblasts in vitro. Oral Surg Oral Med Oral Pathol Oral Radiol Endod. 2009;108(5):707-13.

25. Camargo PM, Lekovic V, Weinlaender M, Vasilic N, Madzarevic M, Kenney EB. Platelet-rich plasma and bovine porous bone mineral combined with guided tissue regeneration in the treatment of intrabony defects in humans. J Periodontal Res. 2002;37(4):300-6.

26. Camargo PM, Lekovic V, Weinlaender M, Vasilic N, Madzarevic M, Kenney EB. A reentry study on the use of bovine porous bone mineral, GTR, and platelet-rich plasma in the regenerative treatment of intrabony defects in humans. Int J Periodontics Restorative Dent. 2005;25(1):49-59.

27. Lekovic V, Camargo PM, Weinlaender M, Vasilic N, Kenney EB. Comparison of platelet-rich plasma, bovine porous bone mineral, and guided tissue regeneration versus platelet-rich plasma and bovine porous bone mineral in the treatment of intrabony defects: a reentry study. J Periodontol. 2002;73(2):198-205.

28. Hanna R, Trejo PM, Weltman RL. Treatment of intrabony defects with bovine-derived xenograft alone and in combination with platelet-rich plasma: a randomized clinical trial. J Periodontol. 2004;75(12):1668-77.

29. Okuda K, Tai H, Tanabe K, Suzuki H, Sato T, Kawase T, Saito Y, Wolff LF, Yoshiex H. Platelet-rich plasma combined with a porous hydroxyapatite graft for the treatment of intrabony periodontal defects in humans: a comparative controlled clinical study. J Periodontol. 2005;76(6):890-8.

30. Dori F, Huszar T, Nikolidakis D, Arweiler NB, Gera I, Sculean A. Effect of platelet-rich plasma on the healing of intrabony defects treated with an anorganic bovine bone mineral and expanded polytetrafluoroethylene membranes. J Periodontol. 2007;78(6):983-90.

31. Dori F, Huszar T, Nikolidakis D, Arweiler NB, Gera I, Sculean A. Effect of plateletrich plasma on the healing of intra-bony defects treated with a natural bone mineral and a collagen membrane. J Clin Periodontol. 2007:34(3):254-61.

32. Dori F, Nikolidakis D, Huszar T, Arweiler NB, Gera I, Sculean A. Effect of platelet-rich plasma on the healing of intrabony defects treated with an enamel matrix protein derivative and a natural bone mineral. J Clin Periodontol. 2008;35(1):44-50.

33. Christgau M, Moder D, Wagner J, Glassl M, Hiller KA, Wenzel A, Schmalz G. Influence of autologous platelet concentrate on healing in intra-bony defects following guided tissue regeneration therapy: a randomized prospective clinical split-mouth study. J Clin Periodontol. 2006;33(12):908-21.

34. Yassibag-Berkman Z, Tuncer O, Subasioglu T, Kantarci A. Combined use of platelet-rich plasma and bone grafting with or without guided tissue regeneration in the treatment of anterior interproximal defects. J Periodontol. 2007;78(5):801-9.

35. Del Fabbro M, Bortolin M, Taschieri S, Weinstein R. Is platelet concentrate advantageous for the surgical treatment of periodontal diseases? A systematic review and meta-analysis. J Periodontol. 2011;82(8):1100-11.

36. Dori F, Arweiler N, Huszar T, Gera I, Miron RJ, Sculean A. Five-year results evaluating the effects of platelet-rich plasma on the healing of intrabony defects treated with enamel matrix derivative and natural bone mineral. J Periodontol. 2013;84(11):1546-55.

37. Agarwal A, Gupta ND. Platelet-rich plasma combined with decalcified freeze-dried bone allograft for the treatment of noncontained human intrabony periodontal defects: a randomized controlled split-mouth study. Int J Periodontics Restorative Dent. 2014;34(5):705-11.

38. Jensen SS, Broggini N, Weibrich G, Hjorting-Hansen E, Schenk R, Buser D. Bone regeneration in standardized bone defects with autografts or bone substitutes in combination with platelet concentrate: a histologic and histomorphometric study in the mandibles of minipigs. Int J Oral Maxillofac Implants. 2005;20(5):703-12.

39. Broggini N, Hofstetter W, Hunziker E, Bosshardt DD, Bornstein MM, Seto I, Weibrich G, Buser D. The influence of PRP on early bone formation in membrane protected defects. A histological and histomorphometric study in the rabbit calvaria. Clin Implant Dent Relat Res. 2011;13(1):1-12.

40. Miron RJ, Fujioka-Kobayashi M, Hernandez M, Kandalam U, Zhang Y, Ghanaati S, Choukroun J. Injectable platelet rich fibrin (i-PRF): opportunities in regenerative dentistry? Clin Oral Investig. 2017. doi:10.1007/s00784-0172063-9. [Epub ahead of print] 
41. Wang X, Zhang Y, Choukroun J, Ghanaati S, Miron RJ. Effects of an injectable platelet-rich fibrin on osteoblast behavior and bone tissue formation in comparison to platelet-rich plasma. Platelets. 2017:1-8. doi:10.1080/09537104.2017.1293807. [Epub ahead of print]

42. Wang X, Zhang Y, Choukroun J, Ghanaati S, Miron RJ. Behavior of gingival fibroblasts on titanium implant surfaces in combination with either injectable-PRF or PRP. Int J Mol Sci. 2017;18(2). doi:10.3390/ijms18020331.

43. Miron RJ, Gruber R, Hedbom E, Saulacic N, Zhang Y, Sculean A, Bosshardt DD, Buser $D$. Impact of bone harvesting techniques on cell viability and the release of growth factors of autografts. Clin Implant Dent Relat Res. 2cr013;15(4):481-9.

44. Wang $Y$, Zhang $Y$, Jing D, Shuang $Y$, Miron RJ. Enamel matrix derivative improves gingival fibroblast cell behavior cultured on titanium surfaces. Clin Oral Investig. 2016;20(4):685-95.

45. Miron RJ, Bosshardt DD, Hedbom E, Zhang Y, Haenni B, Buser D, Sculean A. Adsorption of enamel matrix proteins to a bovine-derived bone grafting material and its regulation of cell adhesion, proliferation, and differentiation. J Periodontol. 2012;83(7):936-47.

46. Miron RJ, Caluseru OM, Guillemette V, Zhang Y, Gemperli AC, Chandad F, Sculean A. Influence of enamel matrix derivative on cells at different maturation stages of differentiation. PLoS One. 2013;8(8):e71008.

47. Fujioka-Kobayashi M, Miron RJ, Hernandez M, Kandalam U, Zhang Y, Choukroun J. Optimized platelet rich fibrin with the low speed concept: growth factor release, biocompatibility and cellular response. J Periodontol. 2017;88(1):112-21.

48. Sawada K, Caballe-Serrano J, Bosshardt DD, Schaller B, Miron RJ, Buser D, Gruber R. Antiseptic solutions modulate the paracrine-like activity of bone chips: differential impact of chlorhexidine and sodium hypochlorite. J Clin Periodontol. 2015;42:883.

49. Kobayashi E, Fluckiger L, Fujioka-Kobayashi M, Sawada K, Sculean A, Schaller B, Miron RJ. Comparative release of growth factors from PRP, PRF, and advanced-PRF. Clin Oral Investig. 2016;20(9):2353-60.

50. Miron RJ, Saulacic N, Buser D, lizuka T, Sculean A. Osteoblast proliferation and differentiation on a barrier membrane in combination with BMP2 and TGFbeta1. Clin Oral Investig. 2013;17(3):981-8.

51. Miron RJ, Hedbom E, Saulacic N, Zhang Y, Sculean A, Bosshardt DD, Buser D. Osteogenic potential of autogenous bone grafts harvested with four different surgical techniques. J Dent Res. 2011;90(12):1428-33.

52. Miron RJ, Oates CJ, Molenberg A, Dard M, Hamilton DW. The effect of enamel matrix proteins on the spreading, proliferation and differentiation of osteoblasts cultured on titanium surfaces. Biomaterials. 2010;31(3):449-60.

53. Fujioka-Kobayashi M, Sawada K, Kobayashi E, Schaller B, Zhang Y, Miron RJ. Recombinant human bone morphogenetic protein 9 (rhBMP9) induced osteoblastic behavior on a collagen membrane compared with rhBMP2. J Periodontol. 2016:87(6):e101-107.

54. Miron RJ, Caluseru OM, Guillemette V, Zhang Y, Buser D, Chandad F, Sculean A. Effect of bone graft density on in vitro cell behavior with enamel matrix derivative. Clin Oral Investig. 2015;19(7):1643-51.

55. Miron RJ, Fujioka-Kobayashi M, Zhang Y, Caballe-Serrano J, Shirakata Y, Bosshardt DD, Buser D, Sculean A. Osteogain improves osteoblast adhesion, proliferation and differentiation on a bovine-derived natural bone mineral. Clin Oral Implants Res. 2017;28(3):327-33.

56. Miron RJ, Chandad F, Buser D, Sculean A, Cochran DL, Zhang Y. Effect of enamel matrix derivative liquid on osteoblast and periodontal ligament cell proliferation and differentiation. J Periodontol. 2016;87(1):91-9.

57. Miron RJ, Fujioka-Kobayashi M, Zhang Y, Sculean A, Pippenger B, Shirakata Y, Kandalam U, Hernandez M. Osteogain (R) loaded onto an absorbable collagen sponge induces attachment and osteoblast differentiation of ST2 cells in vitro. Clin Oral Investig. 2016. [Epub ahead of print]

58. Ghanaati S, Booms P, Orlowska A, Kubesch A, Lorenz J, Rutkowski J, Landes C, Sader R, Kirkpatrick C, Choukroun J. Advanced platelet-rich fibrin: a new concept for cell-based tissue engineering by means of inflammatory cells. J Oral Implantol. 2014;40(6):679-89.

59. Dohan Ehrenfest DM, Doglioli P, de Peppo GM, Del Corso M, Charrier JB. Choukroun's platelet-rich fibrin (PRF) stimulates in vitro proliferation and differentiation of human oral bone mesenchymal stem cell in a dosedependent way. Arch Oral Biol. 2010;55(3):185-94.

60. Plachokova AS, Nikolidakis D, Mulder J, Jansen JA, Creugers NH. Effect of platelet-rich plasma on bone regeneration in dentistry: a systematic review. Clin Oral Implants Res. 2008;19(6):539-45.

61. Griffin XL, Smith CM, Costa ML. The clinical use of platelet-rich plasma in the promotion of bone healing: a systematic review. Injury. 2009;40(2):158-62.
62. Graziani F, Ivanovski S, Cei S, Ducci F, Tonetti M, Gabriele M. The in vitro effect of different PRP concentrations on osteoblasts and fibroblasts. Clin Oral Implants Res. 2006;17(2):212-9.

63. Durmuslar MC, Balli U, Ongoz Dede F, Bozkurt Dogan S, Misir AF, Baris E, Yilmaz Z, Celik HH, Vatansever A. Evaluation of the effects of platelet-rich fibrin on bone regeneration in diabetic rabbits. J Craniomaxillofac Surg. 2016;44(2):126-33.

64. Kokdere NN, Baykul T, Findik Y. The use of platelet-rich fibrin (PRF) and PRF-mixed particulated autogenous bone graft in the treatment of bone defects: an experimental and histomorphometrical study. Dent Res J. 2015;12(5):418-24.

65. Oliveira MR, deC Silva A, Ferreira S, Avelino CC, Garcia Jr IR, Mariano RC. Influence of the association between platelet-rich fibrin and bovine bone on bone regeneration. A histomorphometric study in the calvaria of rats. Int J Oral Maxillofac Surg. 2015;44(5):649-55.

\section{Submit your next manuscript to BioMed Central and we will help you at every step:}

- We accept pre-submission inquiries

- Our selector tool helps you to find the most relevant journal

- We provide round the clock customer support

- Convenient online submission

- Thorough peer review

- Inclusion in PubMed and all major indexing services

- Maximum visibility for your research

Submit your manuscript at www.biomedcentral.com/submit 